\title{
IDENTIFICAÇÃO DE ÁREAS POTENCIALMENTE FAVORÁVEIS PARA A DESTINAÇÃO AMBIENTALMENTE ADEQUADA DE RESÍDUOS SÓLIDOS
}

\author{
Marcos Norberto Boin \\ Universidade Federal da Grande Dourados, Dourados - MS \\ marnorboin@gmail.com \\ João Osvaldo Rodrigues Nunes \\ Universidade Estadual Paulista, Presidente Prudente-SP \\ joao.o.nunes@unesp.br \\ Leonardo da Silva Tomazini \\ Universidade Estadual Paulista, Presidente Prudente-SP \\ thomazini@unesp.br \\ Matheus Naoto Archangelo Okado \\ Universidade Estadual Paulista, Presidente Prudente-SP \\ mna.okado@gmail.com
}

\section{RESUMO}

Muitos são os fatores que se somam para a identificação de áreas adequadas à instalação de aterros sanitários, sendo de ordem física, econômica, social e legislativa. Ta complexidade se respalda nos preceitos da geoecologia, a qual visa o planejamento e a gestão ambiental mediante os fatores físicos e sociais da paisagem. Com isso, este artigo tem como objetivo indicar as alternativas locacionais com a seleção de áreas para disposição de resíduos sólidos, como parte do convênio entre o Consórcio Intermunicipal de Resíduos Sólidos do Oeste Paulista (CIRSOP) e a FCT/UNESP. Para isso, adotou-se uma metodologia baseada em três níveis de análise em suas respectivas escalas: o regional/municipal - municipal/local - local/empreendimento; com a elaboração de materiais cartográficos e a hierarquização das áreas aptas e inaptas. Após a implantação da metodologia, foram delimitadas quatro áreas de maior adequação. Nestas, foram identificadas as feições geomorfológicas que apontam possíveis vulnerabilidade ambiental, tais como erosões, áreas úmidas e de restrições legais. Assim, os resultados obtidos e a metodologia adotada se mostraram adequados no cumprimento do objetivo proposto, sendo eficaz na identificação de áreas ambientalmente adequadas à instalação de aterros sanitários, servindo de referencial metodológico para futuros trabalhos.

Palavras-chaves: Aterro Sanitário. Vulnerabilidade Ambiental. Consórcio Intermunicipal.

\section{OTENTIALLY AREAS FOR THE APPROPRIATE DISPOSAL OF SOLID WAST}

\begin{abstract}
There are many factors to the identification of proper areas for the installation of landfills, such as of physical, economic, social and legislative order. Such complexity is endorsed by the precepts of geoecology, which aims at environmental planning and management through the physical and social factors of the landscape. Thus, this article aims to indicate the locational alternatives with the selection of areas for disposal of solid waste, as part of the agreement between the Intermunicipal Consortium of Solid Waste of West Paulista (CIRSOP) and FCT /UNESP. For that, a methodology was adopted based on three analysis levels in their respective scales: the regional/municipal - municipal/local local/development; with the formulation of cartographic materials and the hierarchy of suitable and unsuitable areas. After the methodology's implementation, four areas of greater adequacy were delimited. In these areas, the geomorphological features that point to possible environmental vulnerability were identified, such as erosions, wet aeras and legal restrictions. Thus, the obtained results and the methodology used proved to be appropriate in fulfilling the proposed goal/objective, being effective in identifying areas that are environmentally suitable for the installation of landfills, serving as a methodological reference for future works.
\end{abstract}

Keywords: Sanitary Landfill. Environmental Vulnerability. Inter-municipal consortium. 


\section{INTRODUÇÃO}

A escolha de uma área para a instalação de um aterro sanitário no contexto do Ecoespaço Intermunicipal, não é uma tarefa fácil e está longe de ser simples, visto que nem todos os 10 municípios participantes do consórcio possuem coleta seletiva. Com isto, o aterro sanitário não será somente para o despejo de rejeitos. Diversos fatores se somam, gerando grande complexidade na escolha das áreas adequadas à instalação do aterro, o que tem proporcionado a elaboração de diversos trabalhos técnicos como o Plano de Gestão de Resíduos Sólidos, de âmbito federal (MMA, 2012) e do Estado de São Paulo (SIMAS, 2014); políticos, com a Política Nacional de Resíduos Sólidos (Lei Federal no 12.305/2010); e acadêmicos (BROLLO, 2001; NUNES, 2002; MONTAÑO et al., 2012; OLIVEIRA, 2014).

Isto porque o ambiente natural é dinâmico com interações entre seus elementos bióticos (fauna e flora) e abióticos (solos, rochas, água), formando um ecossistema que se materializa na paisagem. A estes somam-se os aspectos sociais e políticos, ampliando o conceito de meio ambiente para além daquele de estruturas físicas naturais, com pouco ou nenhuma interferência antrópica, para o de Geoecologia, o qual considera os fatores físicos e sociais para a compreensão da paisagem.

$\mathrm{Na}$ prática metodológica da geoecologia está o planejar a gestão ambiental de uma determinada área, destinada a disposição de rejeitos. Estas, em especial, são exigidas pela Política Nacional de Resíduos Sólidos (Lei Federal no 12.305/10), sendo ainda postulado na referida lei os cuidados necessários e ações proibidas para que não ocorram contaminações (BRASIL, 2010).

De acordo com o MMA - Ministério do Meio Ambiente (2012), ao apresentar os dados de saneamento básico do Brasil, cerca de 99,96\% dos municípios brasileiros têm serviços de manejo de Resíduos Sólidos. Mas, destes, $50,75 \%$ depositam seus resíduos em vazadouros e $22,54 \%$ em aterros controlados, ou seja, restando menos de $30 \%$ dos municípios que destinam seus resíduos sólidos de forma correta, como exigido por lei, em aterro sanitário.

Com o intuído de apresentar áreas mais adequada do ponto de vista ambiental, social e econômico, considerando a complexidade sistêmica do meio ambiente e as normas legais, foram adotadas escalas de análise, como apresentado por Brollo (2001), tendo como base os levantamentos bibliográficos, os quais possibilitaram a produção de materiais cartográficos, através da análise multicritério, permitindo a definição das áreas potenciais a destinação de resíduos.

A divisão da análise em escalas se faz necessário mediante o tamanho da área regional a ser avaliada para a definição da área local de implantação de um aterro sanitário, e por meio desta é possível partir de uma escala média regional chegando em uma escala grande local. Segundo Montaño et al. (2012), o primeiro nível enquadra-se na análise regional e municipal (1:250.000), o segundo aborda as escalas municipal e local (1:100.000). Há ainda, um terceiro nível, o do local e na escala do empreendimento (1:25.000), tratado de forma preliminar, devido a necessidade de realização de trabalho de aferição em campo.

Em cada nível de análise foram adotados critérios específicos, respeitando o nível de detalhe exigido compatível com a escala.

Vale ressaltar, que mesmo com a apresentação das áreas adequadas nos mapeamentos, é imprescindível a experiência da área pelo profissional, bem como as validações em campo.

Assim, foram considerados os aspectos geológicos, pedológicos, geomorfológicos, hidrológico e climático, correspondente as estruturas físicas da paisagem e os aspectos socioeconômicos e legais, referentes às restrições legais, vias de acesso e uso e ocupação da terra.

Em relação às caraterísticas de rocha, solo, relevo e água, compreendendo os atributos geotécnicos, Oliveira (2014) relaciona-os à segurança estrutural e ambiental do local do aterro ao longo de sua vida útil; ao impedimento de contaminação dos recursos hídricos superficiais e de subsuperfície, bem como do ar, do subsolo, da fauna e da flora (cobertura vegetal). Conforme a NBR no 13.826/1997 e Portaria MINTER no 124/1980, fica estabelecida a distância de 200m como área de proteção.

No que concerne aos aspectos socioeconômicos, visou-se minimizar os custos do transporte dos resíduos, o menor impacto nas atividades econômicas das propriedades, das desapropriações das terras, a desvalorização das propriedades adjacentes e as considerações apresentadas pela legislação quanto a aproximação de áreas urbanas, cursos d'água e aeroportos.

Com base nestes critérios, buscou-se a seleção de áreas aptas à disposição de rejeitos, com a elaboração do mapa das áreas aptas e inaptas, nas escalas de 1:250.000, 1:100.000 e 1:25.000, visando o menor impacto ambiental negativo ao meio ambiente, ou seja, o menor risco de contaminação. 
A geração de resíduos sólidos, ação intrínseca as práticas urbano-industriais, são uma das atividades de maior impacto ao meio ambiente, provocando alterações adversas no solo, na água, no ar e na sociedade. Provocadas pelas ações antrópicas, tais alterações compreendem a categoria de danos ambientais oriundos da poluição (ARAÚJO, 2012). E partindo do conceito de geoecologia, aqui apresentado, e ressaltado por Araújo (2012), além da degradação ao meio físico, os danos provocados pela poluição atingem o ser humano individualmente e em sua coletividade.

O processo de contaminação do solo, das águas e do ar, em áreas de disposição de resíduos sólidos é recorrente no Brasil, muito pela falta de estudos adequados e a execução correta do empreendimento. Ao menos no Estado de São Paulo, houve uma melhora na qualidade dos aterros sanitários dos municípios desde 2011 até o mês de maio de 2020 , reduzindo de $23,7 \%$ para $4,4 \%$ os aterros inadequados.

No entanto, os reflexos ambientais de um aterro sanitário não se encerram juntamente com sua vida útil. As produções de chorume e odor continuam por muito tempo e se não forem construídos adequadamente, continuam contaminando o meio ambiente, como exemplificado por Costa (2004) e Lima (2015), ao elencar as condições dos lixões e aterros do município de Belo Horizonte (MG), destacando a contaminação das águas subterrâneas de um antigo lixão que funcionou de 1967 até 1971 - sendo quase 50 anos desativado - por elevadas concentrações de Alumínio, Bário, Chumbo etc.

Os cuidados com os contaminantes também devem ocorrer com os aterros sanitários ainda em atividades, pois seus fluídos, em especial o chorume, possuem alto grau de contaminação, como compara Costa (2004), no trabalho já referenciado, a situação do atual aterro sanitário de Belo Horizonte (MG), que despeja o chorume in natura, de elevada salinidade, altas taxas de coliformes totais e estreptococus fecais ${ }^{1}$, e contaminação bacteriológica, além da presença de materiais pesados e tóxicos, sendo incorporado pelos recursos hídricos.

As caraterísticas geomorfológicas tornam-se um agravante da contaminação pelo chorume, quando os aterros são instalados em declividade elevada e vertente convexa, pois, potencializam o escoamento e a dispersão do material contaminante, como apresentado por Costa e Alves (2011), sobre estudos realizados nos municípios de Dr. Severino e Encanto, no Estado de Rio Grande do Norte.

No roteiro de estudo de investigação de contaminação em áreas de deposição de resíduos sólidos, apresentado pela CETESB (2019), destacam-se as etapas referentes ao conhecimento da profundidade do nível de água, o uso e ocupação de entorno da área de depósito e o perfil litológico, reafirmando a importância das características físicas e socioeconômicas na tomada de decisões quanto a instalação de um aterro sanitário.

Neste aspecto, como pode ser observado, a complexidade na escolha de um local para a implantação de um aterro sanitário requer uma série de critérios a serem avaliados. O uso e cobertura da terra, as características do meio físico, as restrições legais e de segurança, restringem a disponibilidade de áreas próximas aos locais de geração de lixo, com as características demandadas para se implantar um aterro sanitário.

Além dos aspectos mencionados acima, deve-se considerar outros fatores, como planos diretores dos municípios envolvidos, polos de desenvolvimento regional, distâncias de transporte, vias de acesso e os aspectos político-sociais relacionados com a aceitação do empreendimento pelos políticos, pela mídia e pela população local (IBAM, 2001. p. 153).

Outro fator a ser considerado é o econômico-financeiro, uma vez que os recursos financeiros municipais são bastante escassos e a construção e operação de um aterro sanitário exige recursos de grande monta.

Para que sejam atendidos os critérios de forma apropriada, na escolha da área de implantação do aterro sanitário, o IBAM (2001), sugere as seguintes etapas para seleção de áreas para aterro sanitário:

[...] seleção preliminar das áreas disponíveis no município; estabelecimento de um conjunto de critérios de seleção; definição de prioridades para atendimentos aos critérios estabelecidos; análise crítica de cada uma das áreas levantadas frente aos

\footnotetext{
${ }^{1}$ As fezes de animais de sangue quente contêm estreptococos fecais em números relativamente altos, podendo este grupo de bactérias ser utilizado como indicador de poluição fecal no exame de águas (Gaglianone, 1976; Geldreich, 1976). A este respeito, Slanetz e Bartley, 1964 afirmam: "presença de estreptococos fecais em água é uma evidência definitiva de contaminação fecal de origem humana ou animal".
}
Caminhos de Geografia
Uberlândia-MG
v. 23, n. 85
fev./2022
p. $137-156$
Página 139 
critérios estabelecidos e priorizados, selecionando-se aquela que atenda à maior parte das restrições através de seus atributos naturais. (IBAM, 2001. P. 152)

Dentre as fases e critérios apontados pelo IBAM (2001), como estratégia a ser implementada na escolha de área para aterro sanitário estão: critérios técnicos; critérios econômico-financeiros; e critérios político-sociais, sendo ainda, necessária a priorização dos critérios de seleção e a seleção das melhores áreas para a sua posterior análise da área selecionada frente aos critérios utilizados. Após a análise das áreas selecionadas deve-se fazer a ponderação do atendimento aos critérios utilizados e a escolha final da área a ser instalado o aterro sanitário (IBAM, 2001. p. 152).

Neste aspecto, o presente texto tem como objetivo geral indicar as alternativas locacionais com a seleção de áreas para disposição de resíduos sólidos (rejeitos), como parte do convênio entre a CIRSOP (Consórcio Intermunicipal de Resíduos Sólidos do Oeste Paulista) e a FCT/UNESP (Faculdade de Ciências e Tecnologia - Universidade Estadual Paulista). A apresentação dessa metodologia tem como premissa torná-la um instrumento voltado ao planejamento, ao controle e ao gerenciamento ambiental, o que será facilitado pela obtenção de um produto informatizado com ferramentas de geoprocessamento. Este produto é aplicado à definição de uma área para disposição dos rejeitos de 10 municípios visando à implementação de ações voltadas não apenas à operacionalização do setor de resíduos sólidos, mas também à proteção dos recursos naturais.

A área que compreende os dez municípios do Consórcio CIRSOP, está localizada no Oeste do estado de São Paulo, entre as Coordenadas Geográficas $22^{\circ} 24.271$ 'S - 51 56.395 'O e $21^{\circ} 50.926^{\prime} \mathrm{S}$ - 50 $31.713^{\circ} \mathrm{O}$, sobre o Planalto Ocidental Paulista, ocupando uma área total de $6.670,049 \mathrm{~km}^{2}$, conforme as áreas dos municípios apresentada na Figura 1. Estes municípios pertencem as Unidades de Gerenciamento de Recursos Hídricos - UGRHI, Peixe (UGHRI 21), Pontal do Paranapanema (UGHRI 22) e Médio Paranapanema (UGHRI 17).

Figura 1 - Localização dos municípios que compõe o CIRSOP, 2020.

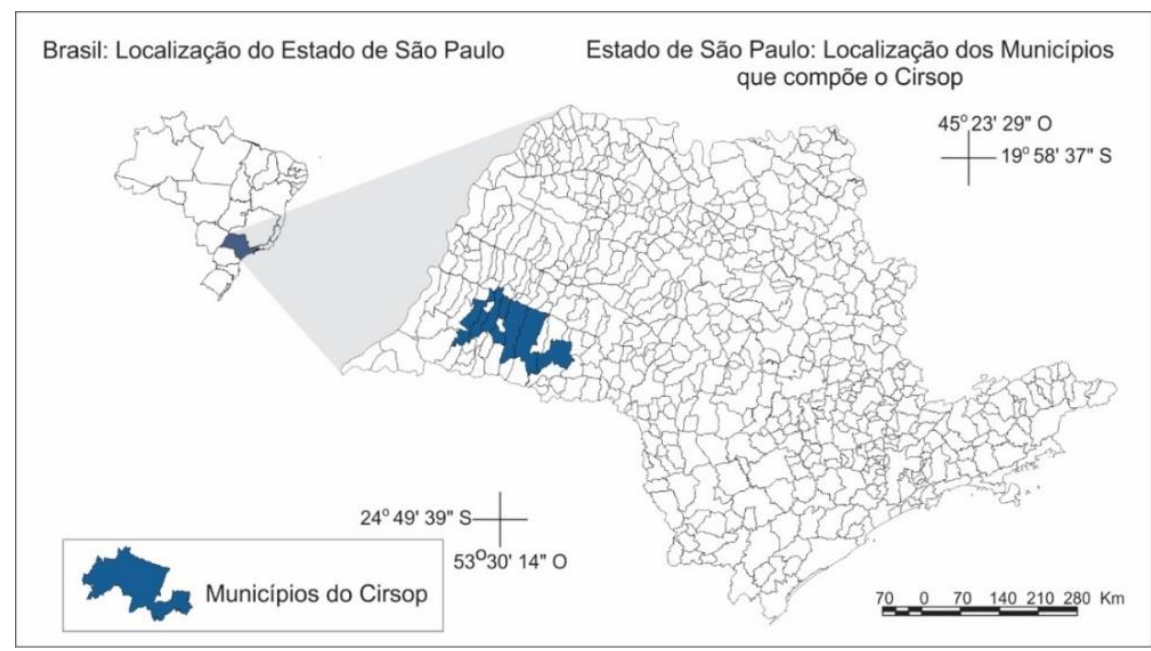

Organização: Autores (2020).

\section{METODOLOGIA}

\section{Nível 1 (Escala 1:250.000)}

A seleção de área para disposição de resíduos sólidos numa escala regional, aqui retratada na escala 1:250.000, segundo Brollo (2001), visa a proteção do meio ambiente e à saúde pública e ainda as possíveis inter-relações entre o empreendimento e o meio ambiente, estando condicionadas ao exame dos aspectos de uso e ocupação da terra e dos aspectos fisiográficos do terreno. Estes aspectos são representados em sua forma final através de duas representações cartográficas, designadas de "Mapa de áreas Legalmente aptas e inaptas para Implementação de Aterro Sanitário" e o "Mapa de Unidades homogêneas da Paisagem, considerando Geologia, Geomorfologia e Pedologia".

$\begin{array}{lllll}\text { Caminhos de Geografia } & \text { Uberlândia-MG } & \text { v. 23, n. } 85 & \text { fev./2022 } & \text { p. 137-156 Página } 140\end{array}$


A integração entre os atributos existentes nestes dois mapas resulta na definição de uma seleção preliminar de áreas potenciais para disposição de resíduos, denominado de: "Mapa de Unidades Homogêneas da Paisagem, e áreas inaptas para Implantação de Aterro Sanitário" (FIGURA 3), cuja elaboração é feita conforme o fluxograma apresentado na Figura 2.

Figura 2 - Articulação da estratégia metodológica do Sistema Gerenciador de Informações voltado à seleção de áreas para disposição de resíduos sólidos - Nível 1, Regional, 2020.

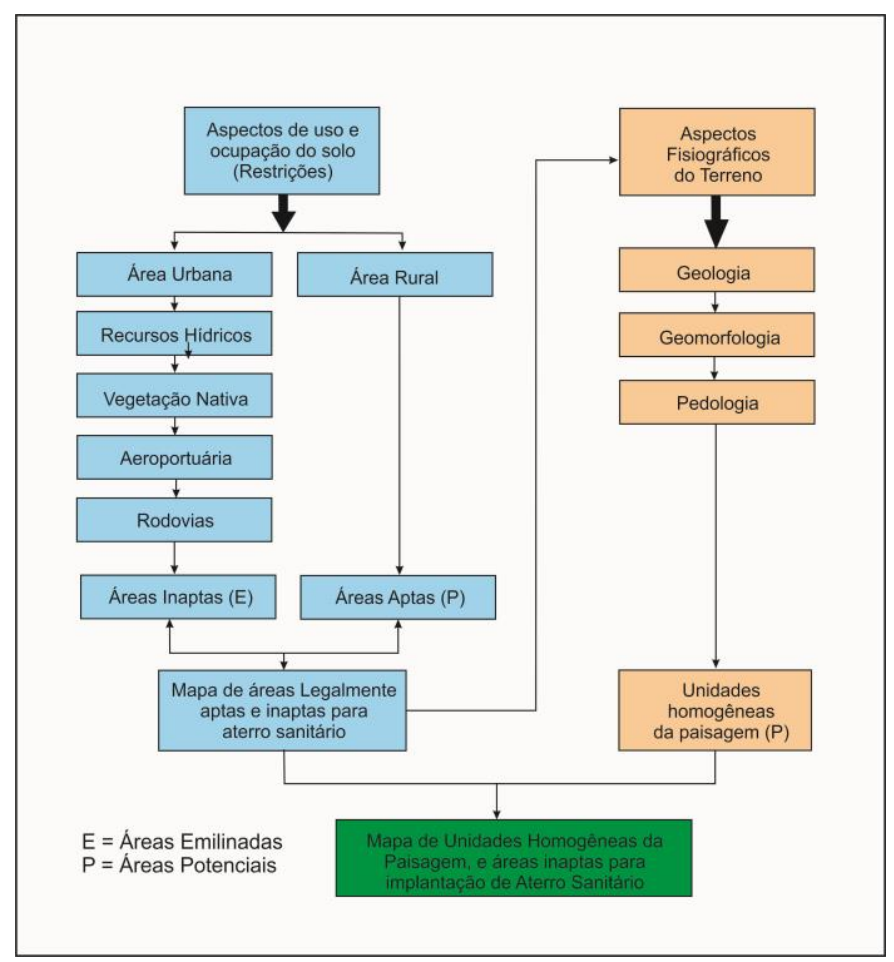

Fonte: Adaptado de Brollo, 2001. 
Figura 3 - Mapa de Unidades Homogêneas da Paisagem com Fatores de Restrição e áreas inaptas para implantação de Aterro Sanitário, na escala 1:250.000, 2020.

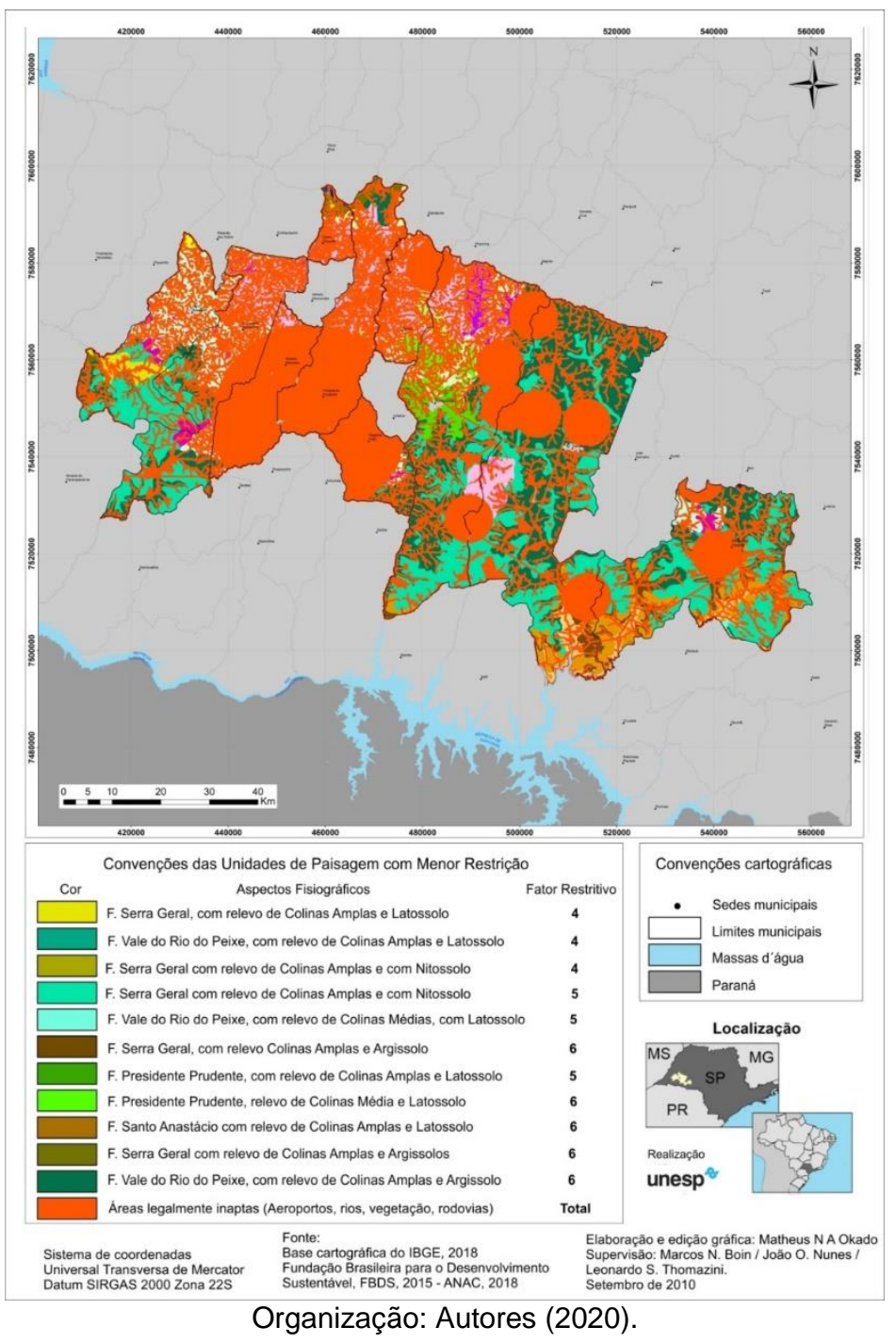

\section{Nível 2 (Escala:1:100.000)}

Neste nível de abordagem, na escala 1:100.000, a seleção de áreas para disposição de resíduos sólidos atendeu aos mesmos critérios anteriores, ou seja, a relação entre os aspectos legais, antrópicos e naturais.

Também neste caso, visou-se a proteção ao meio ambiente, à saúde pública, bem como as possíveis inter-relações entre o empreendimento e o meio ambiente, considerando ainda, à análise dos aspectos de uso e ocupação da terra, dos aspectos fisiográficos do terreno (Geologia, Pedologia, Declividade e Compartimentação do Relevo) e a normativa legal.

Assim, dada a quantidade de aspectos a serem considerados (legais, antrópicos e naturais), para dar suporte à escolha de áreas para o aterro sanitário, optou-se pela utilização de técnicas de inferência geográfica em ambiente SIG (sistema de informações geográficas). Através dessas técnicas é possível integrar todos os aspectos envolvidos e, por meio de modelos e operações, eliminar a ambiguidade nas análises dos aspectos quando estas são feitas individualmente (CÂMARA et al, 2004).

Deste modo, foram empregados três métodos:

temáticos;

A atribuição de pesos e graus de importância relativa para os diferentes mapas

Conversão das bases cartográficas;

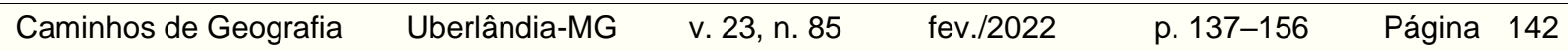



áreas legalmente inaptas.

A aplicação destes métodos é definida de acordo com o fluxograma apresentado na Figura 4, no qual foi gerado o Mapa de Análise Multicritério para Escolha de áreas para Aterro Sanitário e áreas de Restrição Legal com o centro geométrico dos municípios do CIRSOP, na escala 1:100.000 (FIGURA 5).

Figura 4 - Articulação da estratégia metodológica do Sistema Gerenciador de Informações voltado à seleção de áreas para disposição de resíduos sólidos - Nível 2, semidetalhe, 2020.

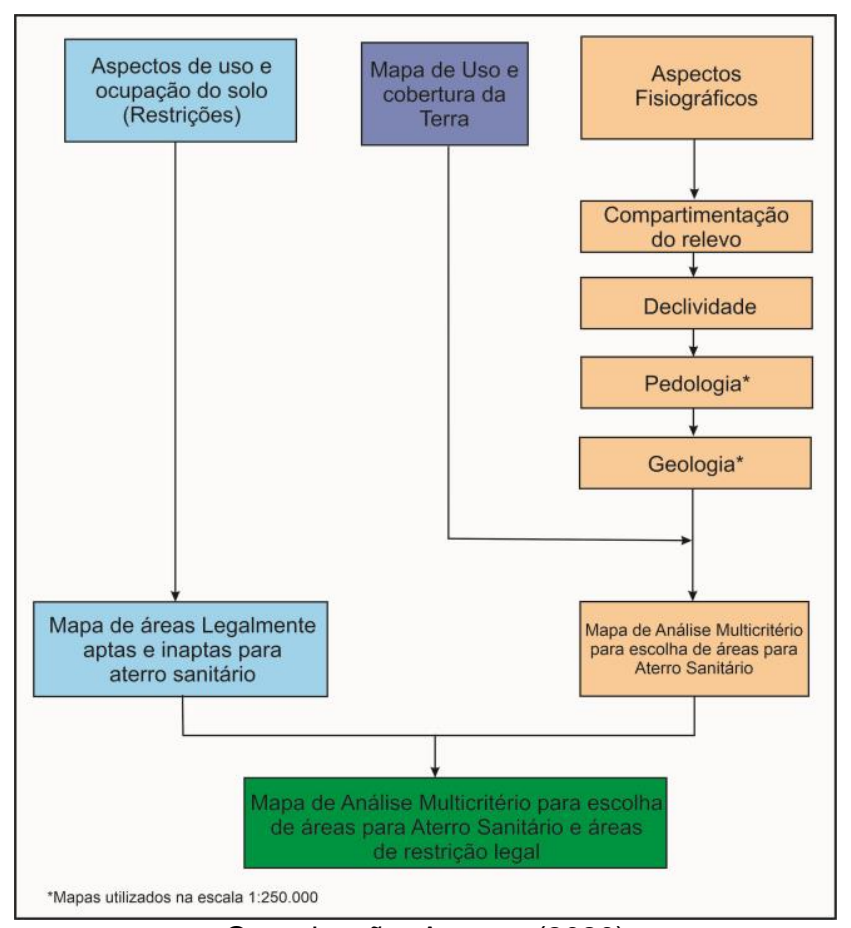

Organização: Autores (2020) 
Figura 5 - Mapa de Análise Multicritério para Escolha de áreas para Aterro Sanitário e áreas de Restrição Legal com o centro geométrico dos municípios do CIRSOP, 2020.

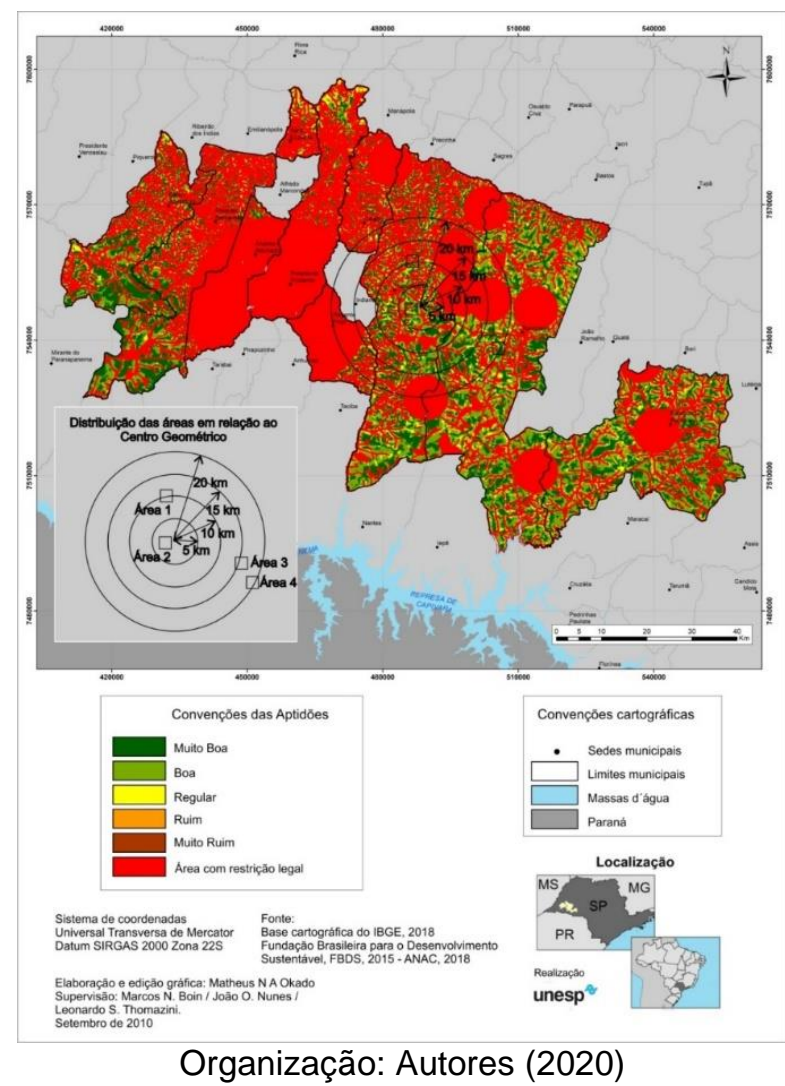

\section{Nível 3 (Escala 1:25.000)}

O terceiro nível de aproximação incide na avaliação de semidetalhe de áreas possíveis para disposição de resíduos sólidos, na qual se realiza uma análise mais detalhada das áreas potenciais definidas no segundo nível. Esta análise ocorre em escala 1:25.000 e leva em conta o refinamento dos parâmetros do meio físico levantados nas escalas 1:250.000 e 1:100.00, além do levantamento de novos aspectos do meio antrópico, somente possíveis nesta escala de abordagem. Como resultado é possível à exclusão de áreas pré-selecionadas no primeiro nível de aproximação, além da definição de alternativas locacionais para a instalação do ECOESPAÇO INTERMUNICIPAL, que abrigue também o ATERRO SANITÁRIO.

A área definida para a avalição na escala 1:25.000, é aquela localizada nos 20 (vinte) primeiros quilómetros no entorno do centro geométrico, encontrado na Coordenada Geográfica $22^{\circ} 10.653^{\prime} S$ $51^{\circ} 6.017^{\prime} O$, onde foram selecionadas quatro áreas, levando-se em consideração as áreas com aptidão BOA e MUITO BOA (FIGURA 5), acessos fáceis e ocupação com pastagens (FIGURAS 6). 
Figura 6 - Sequência de mapas de restrição e uso e ocupação da terra, integrados para a composição do mapa final na escala 1:25.000, 2020.

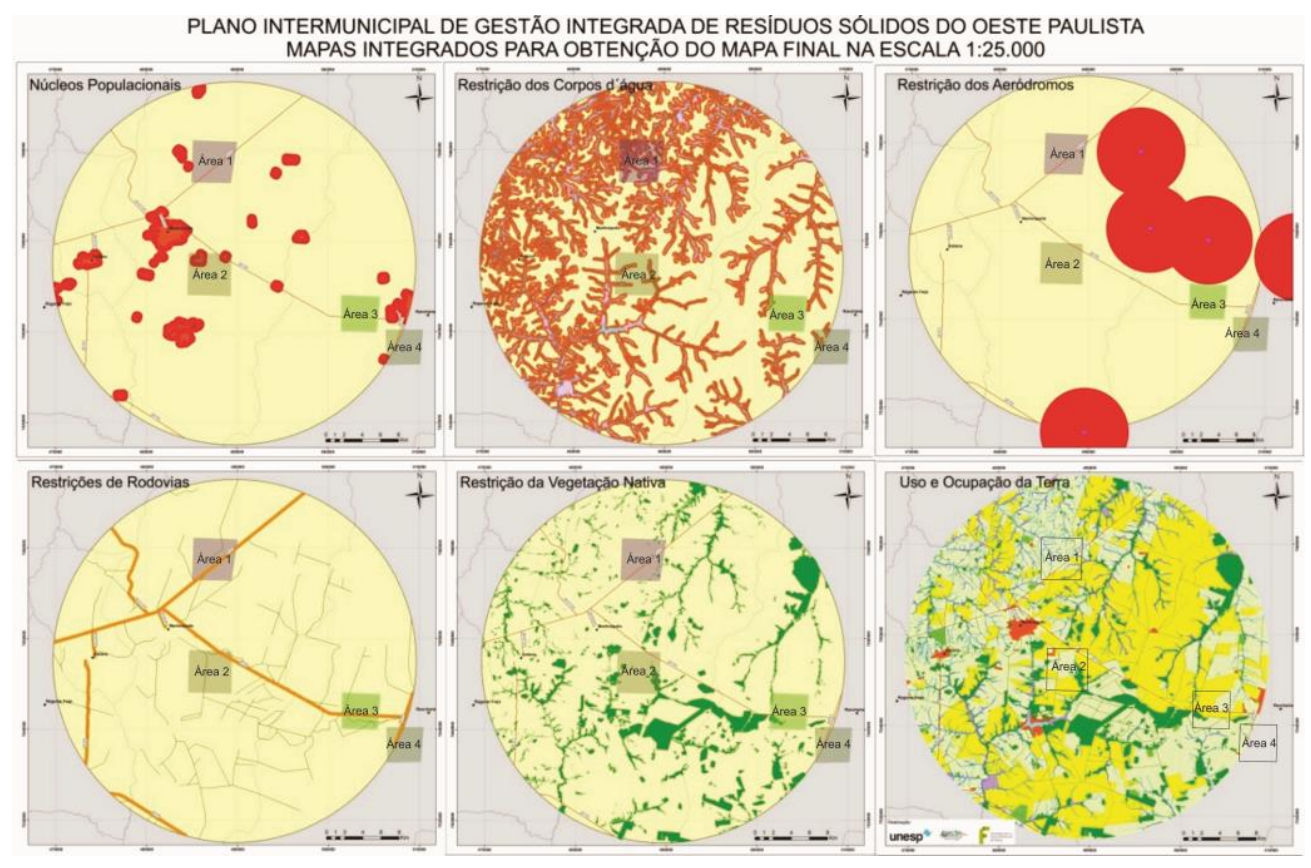

Organização: Autores (2020)

As quatro áreas das quadriculas $01,02,03$ e 04, foram analisadas por imagens de fotografia aéreas da EMPLASA (2010) na escala de 1:25.000 e de satélite Google Earth, respectivamente, com a finalidade de detalhar diferentes aspectos visíveis nas imagens, nesta escala de abordagem. Foram mapeadas pelo programa "StereoPhoto Maker 6.02", com a geração de anaglífos e visualização tridimensional, através da técnica de estereoscopia digital, as feições geomorfológicas como as formas das vertentes, áreas úmidas, divisores d'água, rupturas topográficas e as erosões lineares. Destaca-se que cada uma das quadriculas mapeadas tem superfície maior que 2.000 (dois mil) hectares.

A identificação destas feições geomorfológicas permitiu compreender, dentro das áreas mais adequadas, os setores de maior vulnerabilidade ambiental, ou seja, áreas não visíveis nas escalas menores e que são suscetíveis ao maior dano ambiental mediante a poluição, tais como: as áreas úmidas de média e baixa vertente, onde ocorre o afloramento do lençol freático suspenso; as vertentes convexas que permitem a maior difusão da poluição em caso de vazamento; as vertentes côncavas concentradores de fluxos de escoamento superficial; as feições erosivas indicando maior vulnerabilidade do solo; e as amplitudes das vertentes através das distâncias do fundo de vale com os divisores d'água.

O mapeamento nesta escala ampliou as áreas de restrição, especialmente aquelas associadas às áreas úmidas de cabeceira de drenagem em berço, dos lençóis locais que ocorrem nas rupturas topográficas em médias vertentes, dos lençóis regionais nos fundos de vale, nas planícies aluviais e outras associadas às atividades humanas, tais como a penitenciária de Martinópolis, vilas em sede de propriedades rurais e outros.

\section{RESULTADOS E DISCUSSÃO}

$\begin{array}{lllll}\text { Caminhos de Geografia } & \text { Uberlândia-MG } & \text { v. 23, n. } 85 & \text { fev./2022 } & \text { p. 137-156 Página } 145\end{array}$




\section{Área 1}

A área 1 (FIGURA 7), localiza-se a NWN do Centro Geométrico da área dos municípios do CIRSOP, a 5.800 m no sentido NE da cidade de Martinópolis, na Rodovia Assis Chateaubriand (SP-425). Está situada sobre o divisor de águas entre as bacias hidrográficas do córrego Teresa ou Onze do Ferreira, tributário do ribeirão Mandaguari e córrego da Santa Cândida, tributário do ribeirão dos Guachos, que são afluentes do rio do Peixe.

Figura 7 - Feições geomorfológicas da Área 1, e aspectos do relevo que podem interagir com as atividades do aterro sanitário da CIRSOP, 2020.

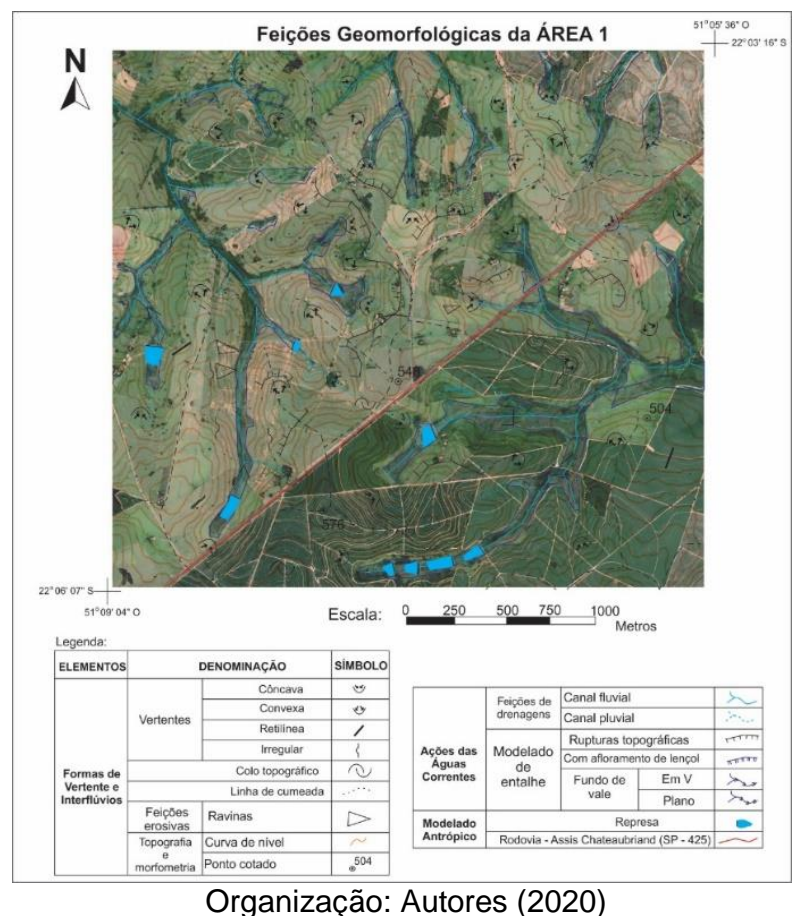

Dista do centro geométrico em linha reta até o centro da quadricula em aproximadamente $11.500 \mathrm{~m}$ na direção NWN. O acesso é realizado pelas rodovias Assis Chateaubriand e Via Coronel João Gomes Martins que sai da Rod. Assis Chateaubriand, indo em direção a Teçaindá e Caiabú. Além das estradas asfaltadas existem outras estradas de terra de aparente bom estado, no interior da área.

Com relação aos aspectos físicos da área, pode-se apontar que os ventos, especialmente aqueles vindos de SE e E, não passam pela cidade de Martinópolis e ainda com relação a cidade de Caiabu e Teçaindá, estas estão a mais de $8 \mathrm{~km}$ de distância, fora da direção preferencial dos ventos. De modo geral, apresentam relevo ondulado, relativamente dissecado, com canais fluviais de $1^{\text {a }}, 2^{\underline{a}}$ e, até $3^{\mathrm{a}}$ ordem.

Nesta área podemos identificar 3 setores distintos, tendo a rodovia Assis Chateaubriand (SP -425$)$ como referencial locacional. O 1 setor é marcado pela própria rodovia, abrangendo as áreas de topos levemente ondulados, se estendendo pelas linhas de cumeada, compreendendo as MELHORES ÁREAS, ou seja, aquelas com menor vulnerabilidade ambiental.

Partindo da rodovia para o Leste - Sudeste ( 2 setor), surgem os canais fluviais que imputem maior ação denudativa no relevo, com vertentes côncavas e convexas mais declivosas e apenas em uma porção, próximo a cota altimétrica de $504 \mathrm{~m}$ é observado uma ampla vertente retilínea. Além do mais, a presença de canais planos propicia grandes áreas úmidas e, com isso, este setor caracteriza-se com menor adequabilidade.

Já o setor que se estende de Oeste a Norte ( $3^{\circ}$ setor), a partir da rodovia, observa-se diversas rupturas topográficas em altas e médias vertentes, sendo que as rupturas de baixa vertente, na maioria dos casos, estão associadas ao afloramento do lençol freático. Na porção Oeste, também,

$\begin{array}{llllll}\text { Caminhos de Geografia } & \text { Uberlândia-MG } & \text { v. 23, n. } 85 & \text { fev./2022 } & \text { p. 137-156 } & \text { Página } 146\end{array}$


são identificados os principais processos erosivos, no caso as ravinas, o relevo é mais dissecado e as drenagens encaixadas, indicando uma denudação do relevo mais intensa. Predominam as formas côncavas e convexas das vertentes e pouca presença de vertentes retilíneas. Tais características indicam que este arco (de Oeste a Norte) é o mais ambientalmente vulnerável e, portanto, o setor MENOS FAVORÁVEL.

O uso e cobertura da terra é composto por $75 \%$ de pastagem e $25 \%$ de cana-de-açúcar, sendo que na parte Oeste da rodovia Assis Chateaubriand, é essencialmente ocupada com pastagem.

\section{Área 2}

Localizada a Sudoeste do Centro geométrico da área dos municípios do CIRSOP, a $5.700 \mathrm{~m}$ a $\mathrm{E}$ da cidade de Martinópolis e $24.900 \mathrm{~m}$ da cidade de Rancharia, na Rodovia Prefeito Homero Severo Lins (SP-284). Está situada sobre o divisor de águas entre as bacias hidrográficas do ribeirão Alegrete e o do córrego do Potrinho, que desaguam na represa do balneário de Martinópolis a $7.100 \mathrm{~m}$, afluentes do ribeirão Da Laranja Doce, afluente direto do rio Paranapanema (FIGURA 8).

Dista do centro geométrico em linha reta até o centro da quadricula em aproximadamente $3.000 \mathrm{~m}$ na direção SW. O acesso é realizado pela rodovia Prefeito Homero Severo Lins, que liga Martinópolis a Rancharia. Além da rodovia mencionada, existem outras estradas de terra de aparente bom estado, no interior da área.

Figura 8 - Feições geomorfológicas da Área 2, e aspectos do relevo que podem interagir com as atividades do aterro sanitário da CIRSOP.

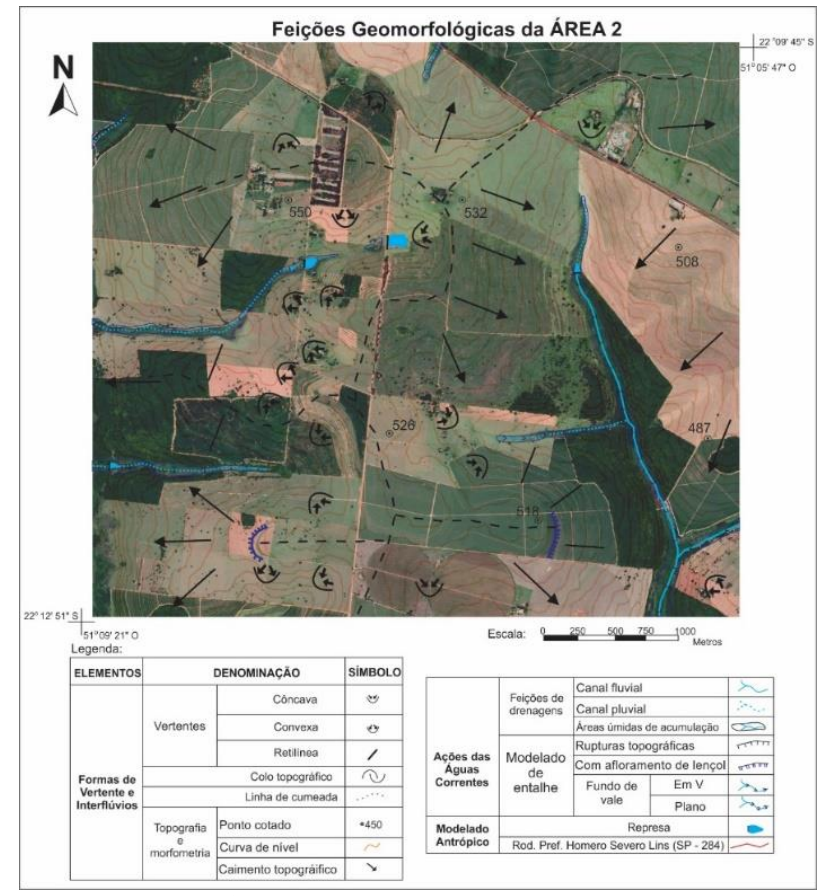

Organização: Autores (2020)

Com relação aos aspectos físicos da área, pode-se apontar que os ventos, especialmente aqueles vindos de SE e E, podem eventualmente atingir a cidade de Martinópolis que se encontra a 5.700 metros do centro da quadrícula.

No que tange aos aspectos do meio físico (relevos, geológicos e pedológicos), as áreas mais FAVORÁVEIS estão localizadas na parte Central, com predomínio de colinas amplas de topos aplainados e ou suavemente ondulados, com baixa declividade, acompanhando a linha de cumeada. As vertentes, de modo geral são retilíneas, com amplos caimentos topográficos. Nestes setores, preponderam os Latossolos profundos e porosos. De modo geral, apresenta baixa densidade de drenagens, sendo a maioria de canais pluviais temporários, e poucos setores com áreas úmidas de

$\begin{array}{lllll}\text { Caminhos de Geografia } & \text { Uberlândia-MG } & \text { v. 23, n. } 85 & \text { fev./2022 } & \text { p. 137-156 Página } 147\end{array}$


acumulação com fundos de vale em $V$ e plano. Não foram identificadas feições erosivas lineares como sulcos, ravinas e voçorocas.

As MENOS FAVORÁVEIS estão situadas em trechos no setor Sul, onde identificou-se rupturas topográficas suave, com afloramento do lençol freático suspenso. Nas cabeceiras de drenagem as vertentes são côncavas, concentradoras de fluxo de escoamento superficial. Como substrato geológico predominam as rochas sedimentares da Formação Vale do Rio do Peixe. O uso e cobertura da terra predominante é o de pastagem.

\section{Área 3}

A Área 3, localiza-se a Leste do Centro geométrico da área dos municípios do CIRSOP, a $24.700 \mathrm{~m}$ a NE da cidade de Martinópolis e a $6.800 \mathrm{~m}$ da cidade de Rancharia, na Rodovia Assis Chateaubriand (SP-425).

Está situada sobre o divisor de águas entre a bacia hidrográfica do Ribeirão Bartira e de seu afluente o córrego Saltinho, tributários do rio do Peixe, na porção Norte da Rodovia Homero Severo Lins. Ao Sul da rodovia, a área situa-se na bacia hidrográfica do ribeirão Capivarí, afluente do rio Paranapanema (FIGURA 9).

Dista do centro geométrico em linha reta até o centro da quadricula por aproximadamente $16.600 \mathrm{~m}$, na direção Leste. O acesso é realizado pela rodovia Prefeito Homero Severo Lins, entre as cidades de Martinópolis e Rancharia. Além da rodovia citada, no interior da área, em sua porção Sul, tem-se a Ferrovia Sorocabana e estradas de terra de aparente bom estado, acompanhando o leito da ferrovia.

Com relação aos aspectos físicos da área, pode-se apontar que os ventos, especialmente aqueles vindos de SE e E, passam pela cidade de Rancharia, antes de passar pela área 3 localizada a mais de 6 quilómetros da malha urbana.

Com relação aos aspectos do meio físico (geológicos, geomorfológicos e pedológicos), é semelhante à descrição efetuada anteriormente sobre a área de $15 \mathrm{~km}$ de raio do centro geométrico. Os extensos interflúvios, com topos levemente ondulados e a ausência de processos erosivos lineares indicam baixa dissecação do relevo, proporcionando à Área 3 grau de MUITO FAVORÁVEL, ou seja, baixa vulnerabilidade, principalmente ao Norte da Rodovia, próximo a cota altimétrica de 577 $\mathrm{m}$. Neste setor, diante das distâncias entre os canais fluviais e baixa declividade, os riscos de danos ambientais, em relação a deposição de resíduos sólidos, são consideravelmente reduzidos. 
Figura 9- Feições geomorfológicas da Área 3, e aspectos do relevo que podem interagir com as atividades do aterro sanitário da CIRSOP, 2020.

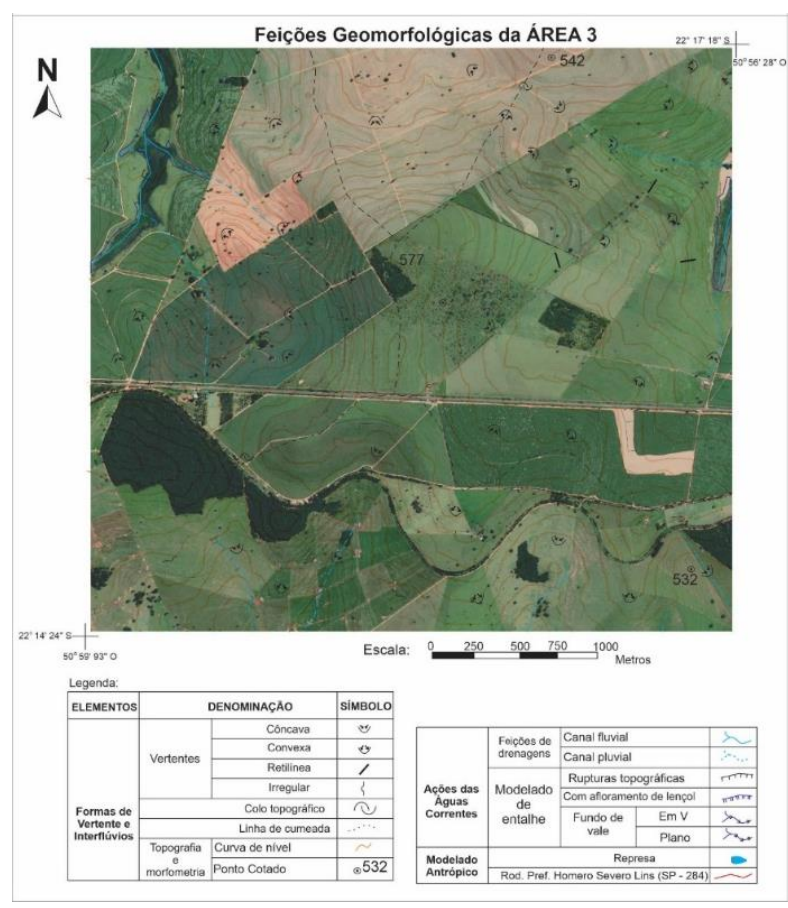

Organização: Autores (2020)

Na porção Sul, mesmo sem a presença de processos erosivos, a presença da Ferrovia Sorocabana impute ao relevo um corte topográfico antrópico que rompe a sequência de baixa declividade na sequência topo-alta vertente, deixando uma área reduzida entre a rodovia e a ferrovia, pois, a partir da ferrovia, as vertentes côncavas e convexas intensificam a declividade até a baixa vertente, fazendo com que ao Sul da Rodovia encontra-se a área MENOS FAVORÁVEL. O uso e cobertura da terra é composto por $75 \%$ de pastagem, $20 \%$ de cana-de-açúcar e um fragmento de vegetação nativa ocupando aproximadamente $5 \%$ da área da quadrícula, junto a ferrovia.

\section{Área 4}

Ao Sul da cidade Rancharia, no divisor de águas entre o ribeirão Capivarí e o ribeirão da Rancharia, localiza-se na Área 4, que dista, $20.500 \mathrm{~m}$ a Leste do centro geométrico da área dos municípios do CIRSOP. A área em questão é cortada pela rodovia Brigadeiro Eduardo Gomes (SP-457) e em seu interior existem somente estradas de terra de propriedades rurais.

Do centro da Área 4 (Figura 10), até a cidade de Rancharia, localizada ao Norte tem-se uma distância de $3.400 \mathrm{~m}$ pela rodovia Brigadeiro Eduardo Gomes. As bacias hidrográficas que compreende a área em apreço são tributárias do rio Paranapanema.

Com relação aos aspectos físicos da área, pode-se apontar que os ventos, especialmente aqueles predominantes vindos de SE e E, não passam pela cidade de Rancharia, pois a posição da área no quadrante SW em relação posição da cidade encontra-se, fora da direção preferencial dos ventos SE e E.

Sobre os aspectos do meio físico (relevos, geológicos e pedológicos) conforme a Figura 10, as áreas FAVORÁVEIS para instalação de aterro sanitário, são os setores Sudoeste e Nordeste, onde predominam as colinas amplas de topos aplainados e ou suavemente ondulados, com baixa declividade, também acompanhando a linha de cumeada. As vertentes, de modo geral são retilíneas, em alguns setores com amplos caimentos topográficos. Nestes setores, também preponderam os Latossolos profundos e porosos.

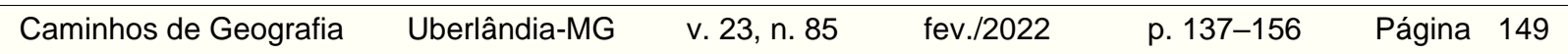


As áreas MENOS FAVORÁVEIS são trechos dos setores, Central e Leste, devido a existência de uma rede de drenagem mais densa, com canais fluviais permanentes e de representativas áreas úmidas de acumulação, com morfologia em berço. Também a existência de vertentes convexas com rupturas topográficas e afloramento do lençol freático suspenso. Além disto, foram identificadas feições erosivas lineares como sulcos e ravinas, em setores das médias baixas vertentes associados as rupturas topográficas. Como substrato geológico predominam as rochas sedimentares da Formação Vale do Rio do Peixe. Na Área 4, o uso e cobertura da terra é essencialmente composta por pastagem.

Figura 10 - Feições geomorfológicas da Área 4, e aspectos do relevo que podem interagir com as atividades do aterro sanitário da CIRSOP.

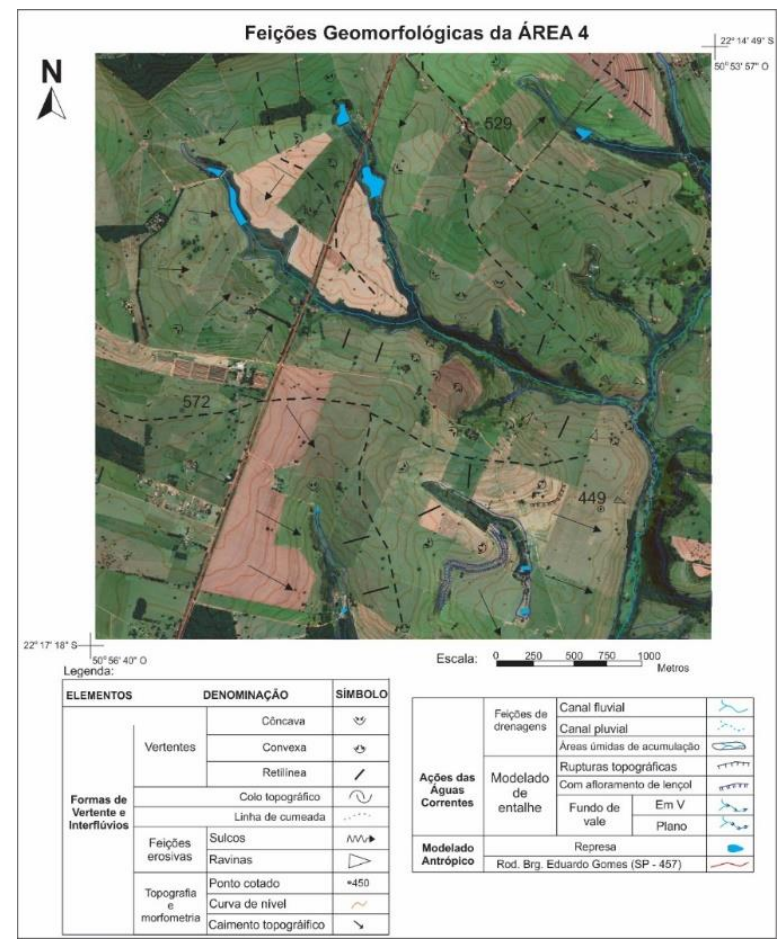

Organização: Autores (2020)

Além dos critérios técnicos levantados e considerados anteriormente neste estudo, ainda segundo o IBAM (2001, p. 154), existem aspectos relacionados às características intrínsecas do solo que dependem de ensaios e análises, como a permeabilidade do solo natural e a disponibilidades de material de cobertura de grande relevância na caracterização e definição da área.

Com relação aos Critérios econômico-financeiros, apontado pelo IBAM (2001, p. 155), o único critério atendido é o da distância ao centro geométrico de coleta, onde se localizam as quatro áreas de análise. Os critérios custo de aquisição do terreno, custo de investimento em construção e infraestrutura e custos com a manutenção do sistema de drenagem, não foram considerados nesta fase de estudos.

Dos três Critérios político-sociais indicados pelo IBAM (2001, p. 155 e 156), dois são atendidos para a área do centro geométrico, os de Distância de núcleos urbanos de baixa renda, e o de Acesso à área através de vias com baixa densidade de Ocupação. $O$ aspecto Inexistência de problemas com a comunidade local, não será abordado por falta de informações.

Aplicando a orientação do IBAM (2001), existente no Manual de Gerenciamento Integrado de Resíduos Sólidos, foram definidas a Hierarquização, prioridades e os pesos necessários a definição das Áreas 1, 2, 3 e 4, apresentadas nas Figuras 7, 8, 9, e 10.

Para escolha da área do aterro foram hierarquizados os diferentes critérios utilizados, de acordo com a seguinte sequência apresentada na Tabela 1.

$\begin{array}{llllll}\text { Caminhos de Geografia } & \text { Uberlândia-MG } & \text { v. 23, n. } 85 & \text { fev./2022 } & \text { p. 137-156 } & \text { Página } 150\end{array}$


Tabela 1 - Hierarquização usada organização das informações para a escolha das áreas.

\begin{tabular}{l|c}
\hline \multicolumn{2}{c}{ HIERARQUIZAÇÃO DE CRITÉRIOS } \\
\hline \multicolumn{1}{c}{ Critério } & Prioridade \\
\hline Atendimento à legislação ambiental em vigor & 1 \\
\hline Atendimento aos condicionantes político-sociais & 2 \\
\hline Atendimento aos principais condicionantes econômicos & 3 \\
\hline Atendimento aos principais condicionantes técnicos & 4 \\
\hline Atendimento a todos os condicionantes econômicos & 5 \\
\hline Atendimento a todos os condicionantes técnicos & 6 \\
\hline *SLAP Sistema de Licenciamento de Atividades Poluidoras. Fonte: Adapt. IBRAM (2001)
\end{tabular}

$\mathrm{Na}$ escolha da melhor área, a análise deve atender aquela que apresenta a maior soma de critérios segundo sua prioridade apontada acima.

Esta escolha foi aplicada em exame individual a cada área selecionada (quatro áreas), com relação aos diversos critérios analisados, existente na Tabela 2.

Tabela 1 - Pesos dos créditos e do tipo de atendimento utilizados no processo de escolha das áreas de aterro sanitário para atender os municípios do CIRSOP. Fonte: Autores (2020)

\begin{tabular}{c|c}
\hline \multicolumn{2}{c}{ Pesos dos critérios e do tipo de atendimento } \\
\hline PRIORIDADE DOS CRITÉRIOS & PESO \\
\hline 1 & 10 \\
\hline 2 & 6 \\
\hline 3 & 4 \\
\hline 4 & 3 \\
\hline 5 & 2 \\
\hline 6 & 1 \\
\hline TIPO DE ATENDIMENTO & PESO \\
\hline Total & $100 \%$ \\
\hline Parcial ou com obras & $50 \%$ \\
\hline Não atendido & $0 \%$ \\
\hline
\end{tabular}

Assim a escolha da melhor área é aquela que atingiu a maior soma de pontos aplicando os pesos, as prioridades e ao atendimento dos critérios elencados anteriormente nas Tabelas 1 e 2 e demonstrados na Tabela 3. 
Tabela 2 - Aplicação dos pesos às prioridades e ao atendimento dos critérios para a escolha das áreas de aterro sanitário para atender os municípios do CIRSOP. Fonte: Autores (2020)

Características das áreas*

\begin{tabular}{|c|c|c|c|c|c|}
\hline \multirow[b]{2}{*}{ CRITÉRIOS* } & \multirow[b]{2}{*}{ PRIORIDADE } & \multicolumn{4}{|c|}{ Atendimento* } \\
\hline & & Área 1 & Área 2 & Área 3 & Área 4 \\
\hline Proximidade a cursos d'água & 1 & 1 & 1 & 1 & 1 \\
\hline Proximidade a núcleos residenciais & 1 & 1 & 1 & 1 & 1 \\
\hline Proximidade a aeroportos & 1 & $P$ & $\mathrm{P}$ & $\mathrm{P}$ & $\mathrm{P}$ \\
\hline Distância do lençol freático & 1 & IñE & IñE & IñE & IñE \\
\hline Distância de núcleos de baixa renda & 2 & 1 & 1 & 1 & 1 \\
\hline Vias de acesso com baixa ocupação & 2 & 1 & I & 1 & 1 \\
\hline Problemas com a comunidade local & 2 & IñE & IñE & IñE & IñE \\
\hline Aquisição do terreno & 3 & IñE & IñE & IñE & IñE \\
\hline Investimentos em infraestrutura & 3 & IñE & IñE & IñE & IñE \\
\hline Vida útil mínima & 4 & 1 & 1 & 1 & 1 \\
\hline Uso do solo & 4 & $P$ & 1 & 1 & 1 \\
\hline Permeabilidade do solo natural & 4 & IñE & IñE & IñE & IñE \\
\hline Extensão da bacia de drenagem & 4 & $P$ & $\mathrm{P}$ & 1 & $\mathrm{P}$ \\
\hline Acesso a veículos pesados & 4 & 1 & 1 & 1 & $P$ \\
\hline Feições geomorfológicas & 4 & $P$ & 1 & 1 & $P$ \\
\hline Material de cobertura & 4 & IñE & IñE & IñE & IñE \\
\hline Manutenção do sistema de drenagem & 5 & IñE & IñE & IñE & IñE \\
\hline Distância ao centro de coleta & 6 & I & I & $P$ & $\mathrm{P}$ \\
\hline
\end{tabular}

Nota: $I$ = atende integralmente; $P$ = atende parcialmente; $N=$ não atende e IñE =Informação não existente (depende de trabalho de campo). * $\mathrm{O}$ atendimento aos critérios técnico e antrópicos aqui apresentados é analisado com a possibilidade de acolhimento em algumas porções e não de toda a extensão da quadricula (> 2.000 ha). Adapt. IBRAM (2001)

Ao aplicarmos os pesos definidos na Tabela 3 , as quatro áreas pré-selecionadas chegaram à pontuação apontada na Tabela 4. 
Tabela 3 - Pontuação das áreas pré-selecionadas para a instalação do aterro sanitário da CIRSOP.

\begin{tabular}{|c|c|c|c|c|c|c|c|c|c|}
\hline \multicolumn{10}{|c|}{ Pontuação das áreas } \\
\hline \multirow[t]{2}{*}{ CRITÉRIOS } & \multirow{2}{*}{$\begin{array}{l}\text { PONTOS DA } \\
\text { PRIORIDADE }\end{array}$} & \multicolumn{4}{|c|}{$\begin{array}{c}\text { PONTOS DE } \\
\text { ATENDIMENTO }\end{array}$} & \multicolumn{4}{|c|}{ PONTUAÇÃO DAS ÁREAS } \\
\hline & & $\begin{array}{l}\text { Área } \\
1 \%\end{array}$ & $\begin{array}{l}\text { Área } \\
2 \%\end{array}$ & $\begin{array}{c}\text { Área } \\
3 \%\end{array}$ & $\begin{array}{l}\text { Área } \\
4 \%\end{array}$ & $\begin{array}{c}\text { Área } \\
1\end{array}$ & $\begin{array}{l}\text { Área } \\
2\end{array}$ & $\begin{array}{c}\text { Área } \\
3\end{array}$ & $\begin{array}{c}\text { Área } \\
4\end{array}$ \\
\hline $\begin{array}{l}\text { Proximidade a } \\
\text { cursos d'água }\end{array}$ & 10 & 100 & 100 & 100 & 100 & 10,0 & 10,0 & 10,0 & 10,0 \\
\hline $\begin{array}{c}\text { Proximidade a } \\
\text { núcleos residenciais }\end{array}$ & 10 & 100 & 100 & 100 & 100 & 10,0 & 10,0 & 10,0 & 10,0 \\
\hline $\begin{array}{l}\text { Proximidade a } \\
\text { aeroportos }\end{array}$ & 10 & 50 & 50 & 50 & 50 & 5,0 & 5,0 & 5,0 & 5,0 \\
\hline $\begin{array}{l}\text { Distância do lençol } \\
\text { freático }\end{array}$ & 10 & IñE & IñE & IñE & IñE & - & - & - & - \\
\hline $\begin{array}{l}\text { Distância de núcleos } \\
\text { de baixa renda }\end{array}$ & 6 & 100 & 100 & 100 & 100 & 6,0 & 6,0 & 6,0 & 6,0 \\
\hline $\begin{array}{l}\text { Vias de acesso com } \\
\text { baixa ocupação }\end{array}$ & 6 & 100 & 100 & 100 & 100 & 6,0 & 6,0 & 6,0 & 6,0 \\
\hline $\begin{array}{l}\text { Problemas com a } \\
\text { comunidade local }\end{array}$ & 6 & IñE & IñE & IñE & IñE & - & - & - & - \\
\hline Aquisição do terreno & 4 & IñE & IñE & IñE & IñE & - & - & - & - \\
\hline $\begin{array}{l}\text { Investimentos em } \\
\text { infraestrutura }\end{array}$ & 4 & IñE & IñE & IñE & IñE & - & - & - & - \\
\hline Vida útil mínima & 4 & 100 & 100 & 100 & 100 & 4,0 & 4,0 & 4,0 & 4,0 \\
\hline Uso do solo & 3 & 50 & 100 & 100 & 100 & 1,5 & 3,0 & 3,0 & 3,0 \\
\hline $\begin{array}{l}\text { Permeabilidade do } \\
\text { solo natural }\end{array}$ & 3 & IñE & IñE & IñE & IñE & - & - & - & - \\
\hline $\begin{array}{l}\text { Extensão da bacia } \\
\text { de drenagem }\end{array}$ & 3 & 50 & 50 & 100 & 50 & 1,5 & 1,5 & 3,0 & 1,5 \\
\hline $\begin{array}{c}\text { Acesso a veículos } \\
\text { pesados }\end{array}$ & 3 & 100 & 100 & 100 & 50 & 3,0 & 3,0 & 3,0 & 1,5 \\
\hline $\begin{array}{c}\text { Feições } \\
\text { geomorfologicas }\end{array}$ & 3 & 50 & 100 & 100 & 50 & 1,5 & 3,0 & 3,0 & 1,5 \\
\hline $\begin{array}{l}\text { Material de } \\
\text { cobertura }\end{array}$ & 3 & IñE & IñE & IñE & IñE & - & - & - & - \\
\hline $\begin{array}{l}\text { Manutenção do } \\
\text { sistema de } \\
\text { drenagem }\end{array}$ & 2 & IñE & IñE & IñE & IñE & - & - & - & - \\
\hline $\begin{array}{c}\text { Distância ao centro } \\
\text { de coleta }\end{array}$ & 1 & 100 & 100 & 50 & 50 & 0,5 & 1,0 & 1,0 & 0,5 \\
\hline $\begin{array}{l}\text { PONTUAÇÃO } \\
\text { FINAL } \\
\end{array}$ & - & - & - & - & - & 49,5 & 52,5 & 53,5 & 49,0 \\
\hline
\end{tabular}

Adapt. IBRAM (2001)

A metodologia aplicada para definição da maior pontuação das quatro áreas selecionadas quantos aos critérios técnicos, econômico-financeiros, político-sociais, culminou com a pontuação apresentada na Tabela - 04, onde se observa que os maiores números de pontos da prioridade (TABELA - 3), recaem sobre critérios técnicos de proteção dos Recursos Hídricos (Proximidade a cursos d'água e Distância do lençol freático) e critérios Político-sociais (Proximidade a núcleos residenciais e Proximidade a aeroportos). Estes quatro critérios fazem parte da prioridade 1, e foram atendidos, segundo a Tabela - 4, em 100\% com relação à Proximidade a cursos d'água e de Núcleos residenciais, $50 \%$ no critério Proximidade de aeroportos, e com relação a Distância do lençol freático, não se tem informações sobre as quatro áreas, pois depende de trabalhos de campo.

Quanto às prioridades 2 (TABELA - 3), os critérios Distância de núcleos de baixa renda e Vias de acesso com baixa ocupação, foram atendidos em 100\% (TABELA -04), para as quatro áreas em

$\begin{array}{llllll}\text { Caminhos de Geografia } & \text { Uberlândia-MG } & \text { v. 23, n. } 85 & \text { fev./2022 } & \text { p. 137-156 } & \text { Página } 153\end{array}$ 
análise e o critério Problemas com a comunidade local, não se obteve informações por falta de trabalhos de campo.

A prioridade 3 , apontada na Tabela -3 , com dois critérios estabelecidos na Tabela - 24 (Aquisição do terreno e Investimento em infraestrutura - TABELA 04) não foi levantada para nenhuma das quatro áreas, por se tratar de decisão que não compete a área técnica de estudo do meio físico.

A partir da prioridade 4 (TABELA - 3) é que se verifica divergência na pontuação entre as quatro áreas conforme a Tabela -4 .

Na prioridade 4 (TABELA - 3), o critério Vida útil mínima (TABELA - 4) é atendido integralmente nas quatro áreas $100 \%$ (TABELA - 4). Os critérios Permeabilidade do solo natural e Material de cobertura, não foram avaliados por falta de trabalhos de campo, investigação direta e indireta e análises laboratoriais. Na prioridade 4, o critério Uso do solo (TABELA - 4) da área "1" atende parcialmente com 50\%, por conter a predominância de uso com cana-de-açúcar, e em menor quantidade, áreas de pastagem com maior possibilidade de aquisição. As áreas "2", "3" e "4", os requisitos de Uso do solo, são atendidas integralmente (100\%).

Quanto ao critério Extensão da bacia de drenagem, prioridade 4, as bacias das áreas "1", "2" e "4", atendem integralmente ao critério (100\%), enquanto as bacias da área " 3 ", só atende parcialmente $(50 \%)$, por existirem interflúvios menores.

O critério Acesso a veículos pesados, é atendido integralmente (100\%) nas áreas "1", "2" e " 3 ", e parcialmente $(50 \%)$, na área " 4 ".

As Feições geomofológicas, foram atendidas integralmente $(100 \%)$ nas áreas "2" e "3", e parcialmente $(50 \%)$ nas áreas " 1 " e " 4 ".

Com relação à prioridade 5 (TABELA - 3), o critério Manutenção do sistema de drenagem (TABELA 4), não foi avaliado por se tratar de obras que devem ser avaliadas após a instalação do aterro sanitário.

Por último a prioridade 6 (TABELA - 3), composta por apenas um critério denominado de Distância ao centro de coleta (TABELA - 4), as áreas "1" e "4" atendem parcialmente (50\%) o critério, e as áreas "2" e " 3 ", integralmente (100\%).

Aplicando os pesos atribuídos aos critérios de prioridade da Tabela - 3, chega-se a soma da Tabela 4 , onde as duas áreas com maior pontuação são as áreas "2", com 52,5 pontos e a área "3" com $53,5,0$ pontos.

Desta forma, as áreas com maiores pontuações são as de número "2" e "3", com pequena diferença, que pode ser revertida com os trabalhos de campo.

A escolha da área 3, deve ser considerada como preliminar, já que uma série de aspectos e critérios só serão possíveis de serem considerados, após a decisão dos gestores do Consórcio Intermunicipal de Resíduos Sólidos do Oeste Paulista auxiliarem financeiramente nos trabalhos de campo.

\section{CONSIDERAÇÕES FINAIS}

Embora a escolha da gleba para o aterro tenha recaído sobre a Área 3, a Área 2 também apresentou muito bom grau de favorável a implantação do aterro e está em posição central aos municípios do CIRSOP.

As áreas indicadas para a disposição de resíduos sólidos dos municípios do CIRSOP, estão a uma distância entre 5 a $12 \mathrm{~km}$ dos centros dos aeroportos privados existentes na área estudada. Caso seja necessário o raio de 20 km, apontado na Portaria 798/GC3 de julho de 2020, do Ministério da Defesa Comando da Aeronáutica, a instalação de aterro sanitário nas áreas dos municípios do CIRSOP será inviável.

Em face da dificuldade com o aspecto segurança aeroportuária, apontado acima, a definição da tecnologia a ser utilizada na área pode resolver este e outros aspectos que possam ser restrições a um aterro sanitário com disposição dos rejeitos sem nenhum tratamento prévio. 
Entende-se que, no caso da área ser destinada a um ECOESPAÇO INTERMUNICIPAL, com tratamentos dos resíduos e destinação ambientalmente correta apenas dos rejeitos, o problema apontado com relação aos aeroportos privados, será contornado.

Como apontado anteriormente há a necessidade dos trabalhos de campo para avaliar e analisar as características do solo e a profundidade do lençol freático, para melhor definir as áreas a serem escolhidas para o aterro. Sem estes elementos, a investigação e análise da vulnerabilidade do solo a erosão e a contaminação, ficam prejudicadas.

A metodologia utilizada neste estudo, de forma a se aprofundar em diferentes níveis de análise até se chegar ao nível do trabalho atingido, se mostrou coerente e condizente com os resultados esperados para estas etapas.

Espera-se que, com os trabalhos de campo, os ensaios e as análises necessárias ao término do trabalho para escolha de área para o ATERRO SANITÁRIO ou o ECOESPAÇO INTERMUNICIPAL, pretendido para a destinação final dos resíduos sólidos dos 10 (dez) municípios do CIRSOP, ter-se-á a comprovação da melhor área possível para atender estes municípios.

\section{REFERÊNCIAS}

ARAÚJO, L. A. de. Danos Ambientais na Cidade do Rio de Janeiro. In: GUERRA. A. J. T.; CUNHA, S. B. da. (Org.) Impactos Ambientais Urbanos no Brasil. 9o Edição. Rio de Janeiro: Bertrand Brasil, 2012. P. $347-403$.

BRASIL. Lei n.․․ 12.305, de 2 de agosto de 2010. Brasília, DF, 2010. Política Nacional de Resíduos Sólidos.

BROLLO, M. J. Metodologia automatizada para seleção de áreas para disposição de resíduos sólidos. Aplicação na Região Metropolitana de Campinas (SP). Tese de Doutorado (Faculdade de Saúde Pública). Universidade de São Paulo - USP, São Paulo. 2001, 324p.

CÂMARA, GILBERTO et al. Técnicas de inferência geográfica. In: CÂMARA, Gilberto et al. Introdução à ciência da geoinformação. São José dos Campos: Divisão de Processamento de Imagens - DPI e Instituto Nacional de Pesquisas Espaciais - INPE, 2004. Cap 9,48p. Disponível em $<$ http//www.dpi.inpe.br/gilberto/livro/introd/>

CETESB - COMPANHIA AMBIENTAL DO ESTADO DE SÃO PAULO. Roteiro para Elaboração de estudos de Investigação de Contaminação em Áreas de Deposição de Resíduos Sólidos urbanos. São Paulo: CETESB, 2019

COSTA, W. D. Contaminação da Água Subterrânea por Resíduo Sólido no Município de Belo Horizonte - MG. In: Congresso Brasileiro de Águas Subterrâneas, n. 13, 2004. Anais do XIII Congresso Brasileiro de Águas Subterrâneas. Disponível em: $<$ https://aguassubterraneas.abas.org/asubterraneas/article/view/23416> . Acesso em: 04 jun. 2020

COSTA, L. B.; ALVES, A. de M. Contaminação de Água por Resíduos Sólidos: uma perspectiva geomorfológica nos municípios de Dr. Severino e Encanto - RN. GeoTemas, Rio Grande do Norte, v. 1, n. 1, p. $79-90$, jan./jun. 2011

EMPLASA - Empresa Paulista de Planejamento Metropolitano S.A. Ortofotos do Estado de São Paulo - 2010 / 2011 (EMPLASA). 01/01/2010

IBAM - Manual de Gerenciamento Integrado de resíduos sólidos / José Henrique Penido Monteiro ... [et al.]; coordenação técnica Victor Zular Zveibil. Secretaria Especial de Desenvolvimento Urbano da Presidência da República - SEDU/PR. Rio de Janeiro. 2001.

LIMA, A. N. Análise do monitoramento da contaminação ambiental no solo do aterro de resíduos sólidos urbanos encerrado de Seropédica. Dissertação de mestrado, 2015. P.166

MDCA - MINISTÉRIO DA DEFESA COMANDO DA AERONÁUTICA. Plano básico de gerenciamento de risco de fauna: manual de orientação. Brasília, 2020

MMA - MINISTÉRIO DO MEIO AMBIENTE. Plano de Gestão de Resíduos Sólidos: manual de orientação. Brasília, 2012

$\begin{array}{lllll}\text { Caminhos de Geografia } & \text { Uberlândia-MG } & \text { v. 23, n. } 85 & \text { fev./2022 } & \text { p. 137-156 Página } 155\end{array}$


MONTAÑO. M. et al. Integração de Critérios Técnicos, Ambientais e Sociais em Estudos de Alternativas Locacionais para Implantação de Aterro Sanitário. Eng. Sanit. Ambient., v. 17, n. 1, p. $61-70$, jan/mar. 2012.

NUNES, J. O. R. Uma contribuição metodológica ao estudo da dinâmica da paisagem aplicada a escolha de áreas para construção de aterro sanitário em Presidente Prudente. 2002. 211 f. Tese (Doutorado em Geografia) - Faculdade de Ciência e Tecnologia, Universidade Estadual Paulista. Presidente Prudente.

OLIVEIRA, R. C. de. Escolha de área para aterro sanitário em meios porosos: 0 caso do município de Anhumas - SP, 2014. 186 f. Dissertação de Mestrado - Universidade do Oeste Paulista - UNOESTE. Presidente Prudente - SP.

SIMAS. A. L. F. et al. Plano de Resíduos Sólidos do Estado de São Paulo. 1르 Edição. São Paulo: SMA, 2014.

Recebido em: 21/09/2020

Aceito para publicação em: 13/10/2021 